See Article page 1989.

\section{Commentary: Preaching beyond the choir}

\author{
Aaron Bettenhausen, MD, and Dawn S. Hui, MD
}

In this edition of the Journal, Bojko and colleagues ${ }^{1}$ report on the fate of aortic insufficiency (AI) after valve resuspension and root reconstruction during repair of acute type A aortic dissections (ATAADs). This concept of root preservation is fostered by the idea that the aortic root is normal before dissection in the majority of patients; thus, AI is likely secondary to acute sinus of Valsalva (SOV) disruption from the dissection. At their institution, the decision to replace the root is based on (1) location of the primary tear; (2) preoperative SOV diameter (>45 mm); and (3) hemodynamic stability. Preoperative severe AI was associated with progression from no AI to mild AI (hazard ratio, 2.14) and progression from mild AI to moderate AI (hazard ratio, 5.7). Of their 539 patients, 4 required reoperation for moderate or greater $\mathrm{AI}{ }^{1}$

Traditionally, the operative approach for patients with ATAAD is one that addresses immediate mortality and morbidity in terms of risk of rupture, tamponade, and organ malperfusion. In the contemporary era, with improvements in preoperative care and operative techniques, there has been more focus on improving long-term outcomes. There is growing literature on the natural history of the aortic root and valve function after repair of ATAAD. Freedom from recurrent AI $2+$ or greater has been reported to be $92 \%$ and $76 \%$ for patients presenting with AI $2+$ or less and $\mathrm{AI} 2+$ or greater, respectively, at 5 years. ${ }^{2}$ What is unclear is whether SOV dilation and recurrent AI are independent events. ${ }^{1,3,4}$ Moreover, it is unclear how significantly the role of medical therapy, such as afterload reduction, plays into these more proximal aortic pathologies.

\footnotetext{
From the Department of Cardiothoracic Surgery, Long School of Medicine, University of Texas Health Science Center at San Antonio, San Antonio, Tex. Disclosures: Authors have nothing to disclose with regard to commercial support. Received for publication Feb 3, 2020; accepted for publication Feb 4, 2020; available ahead of print Feb 14, 2020.

Address for reprints: Dawn S. Hui, MD, Department of Cardiothoracic Surgery, Long School of Medicine, University of Texas Health Science Center at San Antonio, 7703 Floyd Curl Drive, Suite 211L, San Antonio, TX 78229 (E-mail: huid@ uthscsa.edu).

J Thorac Cardiovasc Surg 2021;161:2001-2

$0022-5223 / \$ 36.00$

Copyright (c) 2020 by The American Association for Thoracic Surgery https://doi.org/10.1016/j.jtcvs.2020.02.023
}

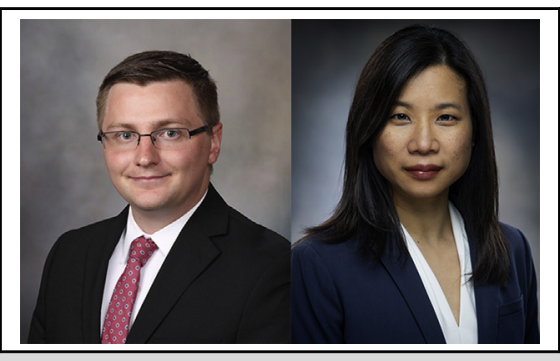

Aaron Bettenhausen, MD, and Dawn S. Hui, MD

$$
\begin{aligned}
& \text { CENTRAL MESSAGE } \\
& \text { Follow-up of patients after } \\
& \text { ATAAD repair with valve preser- } \\
& \text { vation is typically in the hands of } \\
& \text { nonsurgeons, which has implica- } \\
& \text { tions for regionalization of care. }
\end{aligned}
$$

Given the tenuous state in which most of these patients present, the standard approach even at an experienced center remains a conservative approach with root preservation and reconstruction. The authors sagely interpret their data not to mean a lower threshold for root replacement, but rather greater attention to postoperative care and follow-up. This raises an interesting question when it comes to the trend of regionalization of care to high-volume referral centers. The fragmented nature of the American healthcare system means that continuity and quality of care for patients with AI are not necessarily ensured. Immediate operative outcomes may improve, but aortic disease is a chronic condition that should be managed lifelong. Despite thorough efforts by the investigators, echocardiographic follow-up data were available in only $56 \%, 26 \%$, and $7 \%$ at 1,5 , and 10 years, respectively. This may reflect not only the usual difficulty in obtaining data outside one's system but also a failure of provision of appropriate long-term care and surveillance. Lack of surveillance may be correlated with suboptimal afterload reduction, leading to a selection bias of those who did have follow-up available for analysis. Although it is more convenient for those patients who live remotely from the index institution to seek ongoing care locally, there are likely significant variations in the quality of such care with regard to imaging, intensity of afterload therapy, and patient education. Ultimately, while readers of the Journal will be familiar with the guidelines and recommendations for patients with AI, Bojko and colleagues' study ${ }^{1}$ reinforces the need for this message to be conveyed to the larger medical community. 


\section{References}

1. Bojko M, Habertheuer A, Bavaria J, Suhail M, Hu R, Harmon J, et al. Recurrent aortic insufficiency after emergency surgery for acute type A aortic dissection with aortic root preservation. J Thorac Cardiovasc Surg. 2021;161:1989-2000.e6.

2. Pessotto R, Santini F, Pugliese P, Montalbano G, Luciani GB, Faggian G, et al. Preservation of the aortic valve in acute type A dissection complicated by aortic regurgitation. Ann Thorac Surg. 1999;67:2010-3.
3. Ro SK, Kim JB, Hwang SK, Jung SH, Choo SJ, Chung CH, et al. Aortic root conservative repair of acute type A dissection involving the aortic root: fate of the aortic root and aortic valve function. J Thorac Cardiovasc Surg. 2013;146:1113-8. 4. Rylski B, Beyersdorf F, Blanke P, Boos A, Hoffmann I, Dashkevich A, et al. Supracoronary ascending aortic replacement in patients with acute aortic dissection type A: what happens to the aortic root in the long run? J Thorac Cardiovasc Surg. 2013;146:285-90.
See Article page 1989.

\section{Commentary: Recurrent aortic insufficiency after emergency surgery for acute type $A$ aortic dissection with aortic root preservation: "A man's got to know his limitations"}

\author{
Alan M. Speir, MD
}

Aortic insufficiency is a common clinical finding in patients who present with acute type A aortic dissection. The range of severity of this valvular abnormality is quite broad and depends on the underlying structural sequelae of the intimal tear associated with acute aortic dissection. Bojko and colleagues ${ }^{1}$ present their findings from a reputable, single institution study and summarize that the "preoperative degree of aortic insufficiency is significantly associated with increasing probability of developing postoperative aortic insufficiency after root-preserving surgery for acute type A aortic dissection."

The summary seems relatively obvious; however, the authors contend that such long-term outcomes have not been previously well documented following conservative root management with valve resuspension and root repair as the specific aortic clinical presentation. The decision to

From the Department of Cardiac Surgery, Inova and Vascular Institute, Falls Church, Va.

Disclosures: Author has nothing to disclose with regard to commercial support.

Received for publication Jan 23, 2020; accepted for publication Jan 23, 2020; available ahead of print Feb 7, 2020.

Address for reprints: Alan M. Speir, MD, Department of Cardiac Surgery, Inova and Vascular Institute, 3300 Gallows Rd, Falls Church, VA 22042 (E-mail: alan.speir@ inova.org).

J Thorac Cardiovasc Surg 2021;161:2002-3

$0022-5223 / \$ 36.00$

Copyright $₫ 2020$ Published by Elsevier Inc. on behalf of The American Association for Thoracic Surgery

https://doi.org/10.1016/j.jtcvs.2020.01.063
Check for updates

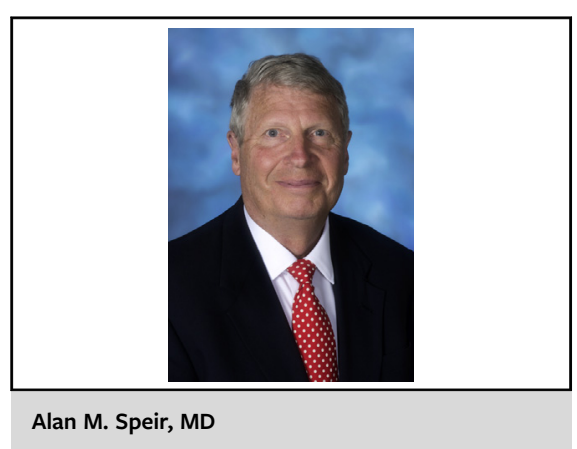

CENTRAL MESSAGE

Because of potential effects on

operative technique or surgical

clinical practice, study limitations

should be mitigated even when

justifiable.

repair rather than replace the root was based on a long-standing model at the University of Pennsylvania Medical Center. Specifically, if the location of the primary tear involves the left or right coronary sinus aortic segment, if the preoperative sinuses of Valsalva diameter is $>45 \mathrm{~mm}$, and if the patient presents in a noncritical clinical state, the surgical approach commonly includes aortic root replacement. Such patients were excluded from this study as well as those with Marfan syndrome or endocarditis.

The limitations of the study are significant. There were the usual single institution, retrospective observational analysis issues. Even more importantly, the authors were not able to document, nor adjust for, the number of dissected sinus segments, a factor that has been shown to be an important predictor of sinuses of Valsalva dilatation and/or aortic insufficiency after root-preserving surgery for type A aortic dissection. ${ }^{2,3}$ They were furthermore not able to differentiate among the different etiologies and mechanisms of aortic insufficiency ${ }^{4}$ in their series. 